\title{
Influence of non-alcoholic malt beverages on urinary excretions of calcium and uric acid
}

\begin{tabular}{ccc}
\hline Kwestan R. Muhammad * & Snjawi A. Sultan ** & Salim K. Mohammed * \\
\hline Abstract &
\end{tabular}

Background and objective: Malt beverage without alcohol (Barbican) is an energy beverage which is regularly consumed by Muslim countries and substantial quantities are exported to the Gulf States and Middle East countries. Barbican is used widely by people whom alcohol is forbidden either on medical grounds or on religious aspects. The aim of this study was to assess the effect of short-term drinking of Barbican on urinary excretion of calcium and uric acid in normal young males in Erbil city.

Methods: Thirty healthy male volunteer subjects of 21-23 years age consumed $330 \mathrm{ml}$ of Barbican ${ }^{\circledR}$ beverage per day for two successive days after cross design. The urinary calcium and urinary uric acid were evaluated before and after consumption.

Results: There was no statistically significant increase in urinary uric acid before and after consumption of Barbican beverage $(P=0.071)$. Urinary calcium significantly decreased after consumption of Barbican drink ( $P=0.037)$.

Conclusion: Although many extrinsic and intrinsic factors influence formation of kidney stones and bone resorption, this study suggests that drinking of Barbican beverage may be helpful to prevent bone resorption and also to reduce risk of stone formation.

Keywords: uric acid, calcium, Barbican, urinary excretion.

\section{Introduction}

Malt beverage is one of the world's oldest ${ }^{1}$ and most widely consumed drinks and the third most popular drink overall after water and tea. ${ }^{2}$ Malt beverage without alcohol (Barbican) is used widely by people whom alcohol is forbidden either on medical grounds or on religious aspects, because of short-term effects of alcohol consumption include intoxication and dehydration. Long-term effects of alcohol include changes in the metabolism of the liver and brain and addiction to alcohol (alcoholism). ${ }^{3-6}$ Over the last decade much attention has been directed to reduce the risks of kidney stone by dietary consumption. ${ }^{7}$ Kidney stones are made up of acid salts and minerals. Calcium, calcium oxalate and ammonium phosphate, cysteine, uric acid, and other substances in the urine are able to form a hard mineral which is called kidney stone (nephrolithiasis). ${ }^{8,9}$ The risk factors for kidney stones are insulin resistance, obesity, living in warmer climates, gastrointestinal pathology, medications and certain dietary patterns. Studies have also shown that insulin resistance can develop renal stones. $^{10,11}$ In addition, epidemiological factors can cause stone formation like genetics, diet, sex, age, and geographic location. $^{12,13}$ Nephrolithiasis can be prevented by nutritional supplements, dietary modifications, and medications depending on type of kidney stone and urine characteristics. ${ }^{10}$ In obese adults, low urinary $\mathrm{pH}$ may cause uric acid nephrolithiasis. $^{11,14,15}$ Furthermore, coronary arterial calcium (CAC) is more common and severe in patients with chronic kidney disease (CKD), and is more strongly associated with an increased risk of cardiovascular disease (CVD). ${ }^{16}$ Uric acid is more likely to form into crystals when there is a hyperurecemia leading to a medical condition known as gout which is

* Department of clinical biochemistry, college of health sciences, Hawler Medical University, Erbil, Iraq.

** Department of laboratory, Hawler Teaching Hospital, Erbil, Iraq. 
caused by elevated levels of uric acid in the blood, the uric acid crystallizes and deposits in joints, tendons, and surrounding tissues. ${ }^{10}$ The effect of this Barbican is usually attributed to increased total urinary calcium loss, and the biochemical explanation is that parathyroid hormone (PTH) primarily controls calcium levels in human blood. When the brain senses low calcium, it triggers the release of PTH, which acts in a complex manner on three major body parts (intestines, bones, and kidneys) to restore or increase calcium levels. PTH causes calcium release from bone as it causes osteoclasts to increase in size, and number, leading to enhanced osteoclast activity and bone resorption (bone loss). ${ }^{17}$ The issue is especially important today because calcium intakes in our region fall far short of current recommendations (1000-1300 mg/dl). ${ }^{18}$ Per capita, Barbican beverage consumption has risen dramatically, and has replaced milk in the diet of most Iraqi Kurdistan region adolescents and adults and with carbonated beverages, carbonated sodas and energy drinks is now the preferred beverages of young individuals. This increase in consumption of soft drinks is not a surprise because soft drink manufactures have spent billions of dollars in advertising to attract more consumers and to increase consumption of their products. Accordingly and because of the interest among nutritionists and dietitians as to the possible effects of Barbican beverage, we have conducted the present study. Although the effect of many beverage on kidney stone risk factors has been reported but the effect of Barbican beverage is not well documented. Thus, we investigated the short-term effects of consuming Barbican beverage on urinary excretion of calcium and uric acid in healthy young males in Erbil city.

\section{Methods}

\section{Experimental design}

This study was carried out during the period April to July 2013 at the Department of Clinical Biochemistry, College of Health Sciences, Hawler Medical University, Erbil, Iraq. Study subjects were divided into two groups, G1 (pre-barbican) and G2 (post barbican). Total urinary calcium and uric acid were measured by enzymatic colorimetric methods. Subjects were 30 healthy male young adults (21-23 years age) who have taken $330 \mathrm{ml} /$ day of Barbican for two successive days (G2), in the morning after overnight fasting before brushing teeth. Subjects were not on a drug or alcohol and none of them had biochemical evidence of any types of disease. Pre-and post- Barbican consumption 24 hours urine samples were collected in (-20 C $).{ }^{19}$ After freezing, total urinary calcium and uric acid levels were estimated. The Barbican beverage was purchased from public markets and it is a popular brand that is commercially available. A relevant statement on permission and ethical practices was approved by the Research Ethics Committee in the College of Pharmacy.

\section{Principle of urinary calcium:}

Total urinary calcium and uric acid were estimated by enzymatic colorimetric methods as described by Tietz $^{20}$ using commercial kits (BIOLABO SA, France). The principle for calcium method was described by Morehead and Brigge, ${ }^{21}$ and depends on the reaction of O-CresolPhtalein (CPC) with calcium in an alkaline medium to form a dark red colored complex. The absorbance measurements were taken at $570 \mathrm{~nm}$ using spectrophotometer (Bio-Tek).

\section{Principle of urinary uric acid:}

Uricase acts on uric acid to produce allantoin, carbon dioxide and hydrogen peroxide. Hydrogen peroxide in the presence of peroxidase reacts with a chromogen (aminoantipyrine and dichlorohydroxybenzen sulfonate) to yield quinonimine which is red colored complex. $^{22}$ The absorbance was measured at $520 \mathrm{~nm}$ using spectrophotometer (Bio-Tek) in proportional to the amount of uric acid in the specimen and the blank was water. 


\section{Statistical analysis}

The statistical evaluations of the results including the mean, and standard error were calculated using the statistical package for the social sciences (version 15.0). The different variables were compared to each other; the paired t test (before and after) was used. A $P \leq 0.05$ was regarded statistically significant. ${ }^{23}$

\section{Results}

Characteristics of the studied groups are shown in Table 1. Table 2 provides the mean \pm SE of total urinary calcium and uric acid excretions in the studied groups. The results obtained indicated that the mean $( \pm S E)$ total urinary calcium was $49.407 \pm$ $2.817 \mathrm{mg} / \mathrm{dl}$, in (G1). This value was higher significantly than that obtained in (G2) $(39.937 \pm 3.007 \mathrm{mg} / \mathrm{dl}) \quad(P=0.037)$. Results revealed an increase in uric acid level but the increase was not significant $(P=0.071)$. Significant changes before and after consumption of $330 \mathrm{ml}$ per day for two successive days of Barbican drink in urinary calcium (G2) levels $(P=0.037$ according to paired t-test with a mean $( \pm$ SE) value of $9.47 \pm 4.32$. No significant differences were also observed $(P>0.05)$ according to a paired t-test before and after consumption of Barbican beverage of urinary uric acid levels. Details are presented in Table 2.

\section{Discussion}

Previous studies were carried out but not on the same approach. They mainly showed that the effect on serum blood of adolescents. Whereas, we have observed significant effects of Barbican drink of urinary excretion on middle age male subjects. The most interesting aspect of our research was a significant decrease $(P<0.05)$ in total urinary calcium excretion after consumption of Barbican drinks. As a result Barbican beverages have significant intrinsic effects on calcium economy. However, even a small excess of urinary excretion, if cumulative and not offset by additional calcium absorption would inevitably lead to hypocalcemia, hypercalciuria and bone loss. Ascorbic acid and apple flavor are one of the ingredients of Barbican beverage which have been widely reported that have a strong antioxidant capacity. Researchers have shown that high intakes of oxalate and sodium and low intakes of magnesium, potassium, and calcium might be contributed to stone formation; also fructose consumption recently has been shown to be a risk factor for kidney stone formation. ${ }^{24}$ Citrate is a known endogenous inhibitor of calcium oxalate stone formation. It forms soluble complexes with calcium and reduces urinary super

Table 1: Number and the (Mean \pm S.E.) of ages of the studied group.

\begin{tabular}{llll}
\hline Group & Number of subjects & Age (Mean \pm S.E.) (years) & Range (years) \\
\hline The studied group & 30 & $22.077 \pm 0.827$ & $21-23$ \\
\hline
\end{tabular}

Table 2: The Mean \pm S.E. of total urinary calcium and uric acid excretions in the studied group.

\begin{tabular}{llllll}
\hline $\begin{array}{l}\text { Biochemical } \\
\text { parameters }\end{array}$ & $\begin{array}{l}\text { Readings before } \\
\text { Barbecan } \\
\text { (Mean } \pm \text { S.E.) }\end{array}$ & Range & $\begin{array}{l}\text { Readings after } \\
\text { Barbecan } \\
\text { (Mean } \pm \text { S.E.) }\end{array}$ & Range & $\boldsymbol{P}$ value \\
\hline $\begin{array}{l}\text { Total urinary } \\
\text { calcium mg/L }\end{array}$ & $49.407 \pm 2.817$ & $13.46-67.64$ & $39.937 \pm 3.007$ & $11.25-67.99$ & 0.037 \\
$\begin{array}{l}\text { Total urinary } \\
\text { uric acid } \mathrm{mg} / \mathrm{L}\end{array}$ & $631.666 \pm 101.355$ & $100-2550$ & $893.33 \pm 73.64$ & $350-2150$ & 0.071 \\
\hline \hline
\end{tabular}


saturation of calcium oxalate. ${ }^{25}$ Urine citrate may be significantly increased by ingesting beverages that are high in citrate content. $^{26}$ So far, several studies have tested various beverages, including other lemonade-based preparations, orange juice, diet sodas, and others, with equivocal results. In addition, a single retrospective study noted that patients on lemonade therapy demonstrated a decreased stone recurrence rate. $^{27}$ Heaney and Rafferty conducted a study that showed association between the excess calciuria with consumption of carbonated beverages, ${ }^{28}$ while Bhowmik et al revealed that malt contain Vitamin $\mathrm{E}$ which has a powerful antioxidant that can prevent low-density lipoprotein (LDL) oxidation effectively. ${ }^{29}$ Knight et $\mathrm{al}^{30}$ have reported that fructose content of diet did not cause stone risk parameters such as urinary excretion of calcium, uric acid, oxalate and urinary $\mathrm{pH}^{31}$ Furthermore, Kovacevic et al, demonstrated that hypercalciuria followed by hypocitraturia has been considered main metabolic risk factor in formation kidney stones in adults and children. ${ }^{32}$ Recent papers reported that citrate can inhibit stone formation and growth. Citrate in the renal tubule binds with calcium to increase its solubility and prevent agglomeration, nucleation, and growth of calcium phosphate crystals and calcium oxalate. ${ }^{33}$ The hyperurecemic effect of alcohol has since been observed in many studies. Most recently NHANES III $^{34}$ was used to assess the impact of various alcoholic beverages on the both serum and urinary uric acid levels. Increased uric acid production and decreased uric acid excretion have both been implicated in the pathogenesis of alcohol-induced hyperurecemia. The health professionals follow-up study, also found that the risk of gout is increased with increasing intake of total beer, followed by spirits, compared with those who did not drink. Beer, like Barbican beverages has a high content from malt of the readily absorbable purine guanosine, which can further increase uric acid production.
This problem is not avoided by the urinary excretions of uric acid or use of reducedcarbohydrate. ${ }^{34}$ There is a limitation in this study; selected factor for raised calcium excretion was Barbican drinks. However, other factors that were not evaluated in this study could be those related to diet and lifestyle. $^{35}$

\section{Conclusion}

The decrease calciuria is confined to normal males who are habitual consumers of Barbican beverage and this is one of the benefits of barley in the non-alcoholic drink. These findings suggest that this result will not be an encouragement for young people to switch drinking milk to the Barbican beverage to retrieve calcium to the body, because the benefits of milk and the introduction of calcium into the body do not compare this brew in terms of calcium to retrieve. Further studies in stone formation are required to understand the exact mechanism and this finding have a beneficial clinical effect.

\section{Conflicts of interest}

The authors report no conflicts of interest.

\section{References}

1. EL-Naggar AY, Arida H, Montasser M, Hassan R. Measures affecting alcohol in malt beverages according to Islamic religion. J Am Sci 2012; 8(10):455-60.

2. Safreit D. Written communication from Brain Shrager, Midwest Research Institute, Cary, NC, to Dallas Safreit, U.S. Environmental Protection Agency, Research Triangle Park, NC; 1994.

3. Nutt D, King LA, Saulsbury W, Blakemore C. Development of a rational scale to assess the harm of drugs of potential misuse. The Lancet 2007; 369(9566):1047-53.

4. Meyer, Jerold S, Quenzer LF. Psychopharmacology: Drugs, the Brain, and Behavior. Sunderland, Massachusetts: Sinauer Associates, Inc; 2005; P. 228.

5. Oscar-Berman M, Marinkovic K. Alcoholism and the brain: an overview. Alcohol Res Health 2003; 27(2):125-33.

6. Klatsky AL, Friedman GD. Alcohol and longevity. Am J of Public Health 1995; 58(1):16-8.

7. Penniston KL, Nakada SY. Diet and alternative therapies in the management of stone disease. Urol Clin N Am 2013; 40:31-46. 
8. Shimizu $T$, Kitada $H$, Umeyama $M$, Hori $H$, Takasaki N. Noval evaluation of nephrolithiasis as a complication of gout: A cross-sectional study using helical computerized tomography. J Urology 2013; 189:1747-52.

9. Copelovitch L. Urolithiasis in children. Pediatr Clin N Am 2012; 59:881-96.

10. Frassetto L, Kohlstadt I. Treatment and prevention of kidney stones: An update. Am Fam Physician 2011; 84(11):1234-42.

11. Tiwari R, Campfield T, Wittcopp C, Braden G, Visintainer $P$, Reiter EO, et al. Metabolic Syndrome in Obese Adolescents is Associated with Risk for Nephrolithiasis. J Pediatr 2012; 160:615-20.

12. Sweeney DD, Tomazewski JJ, Ricchiuti DP, Averch TD. Effect of carbohydrate-electrolyte sports beverages on urinary stone risk factors. J Urology 2009; 182:992-7.

13. Meschi T, Nouvenne A, Borghi L. Lifestyle recommendations to reduce the risk of kidney stones. Urol Clin N Am 2011; 38(3):313-20.

14. Bagga HS, Chi T, Miller J, Stoller ML. New insights into the pathogenesis of renal calculi. Urol Clin N Am 2013; 40:1-12.

15. Eisner BH, Goldfarb DS, Pareek G. Pharmacologic treatment of kidney stone disease. Urol Clin N Am 2013; 40:21-30.

16. He J, Reilly M, Yang W, Chen j, Go AS, Lash JP, et al. Risk factors for coronary artery calcium among patients with chronic kidney disease (from the chronic renal insufficiency cohort study). Am J Cardiol 2012; 110:1735-41.

17. Barger-Lux MJ, Heaney RP. Caffeine and the calcium economy revisited. Osteoporosis Int 1995; 5:97-102.

18. Ross AC, Taylor CL, Yaktine AL, Del HB. Vitamin $D$ and Calcium: updated dietary reference intakes. Available at (http://www.hc-sc.gc.ca/fnan/nutrition/vitamin/vita-d-eng.php) in 25 June 2014.

19. Goldfarb DS, Arowojolu O. Metabolic Evaluation of First-time and Recurrent Stone Formers. Urol Clin N Am 2013; 40:13-20.

20. Tietz NW. Text book of clinical chemistry. $3^{\text {rd }}$ Ed. USA: WB Saunders; 1999.

21. Moorehead WR, Briggs HG. Clinical chemistry. USA: WB Saunders; 1974

22. Fossati P, Prencipe L, Berti G. Use of 3, 5-dichloro-2-hydroxybenzene sulfonic acid/ 4 amino phenazone chromogenic system in direct enzymatic assays of uric acid in serum and urine. Clin Chem 1980; 26:227-31.

23. Daniel WW. Biostatistics: A foundation for analysis in the health science. $3^{\text {rd }}$ Edition. USA: John Wiley and Sons; 1983.

24. Taylor EN, Curhan GC. Fructose consumption and the risk of kidney stones. Kidney Int 2008; 73:207-12.
25. Kok DJ, Papapoulos SE, Bijvoet OL. Excessive crystal agglomeration with low citrate excretion in recurrent stone-formers. Lancet 1986; 1:1056-8.

26. Seltzer MA, Low RK, McDonald M, Shami GS Stoller ML. Dietary manipulation with lemonade to treat hypocitraturic calcium nephrolithiasis. J Urol 1996; 156:907-9.

27. Kang DE, Sur RL, Haleblian GE, Fitzsimons NJ, Borawski KM, Preminger GM. Long-term lemonade based dietary manipulation in patients with hypocitraturic nephrolithiasis. J Urol 2007; 177:1358-62.

28. Heaney RP, Rafferty K. Carbonated beverages and urinary calcium excretion. Am J Clin Nutr 2001; 74(3):343-7.

29. Bhowmik D, Kumar S, Paswan S, Sirvastava S. Tomato - A natural medicine and its health benefits. Phyto J 2012: 1(1):33-43.

30. Knight J, Assimos DG, Easter L, Holms RP Metabolism of fructose to oxalate and glycolate. Horm Metab Res 2010; 42(12):868-73.

31. Eisner BH, Asplin JR, Goldfarb DS, Ahmad A, Stoller ML. Citrate, malate and alkali content in commonly consumed diet sodas: Implications for Nephroliathiasis Treatment. J Urology 2010; 183:2419-23.

32. Kovacevic L, Christensen CW, Edwards L, Sadaps M, Lakshmanan Y. From hypercalciuria to hypocitraturia- A shifting trend in pediatric urolithiasis? J Urology 2012; 188:1623-7.

33. Zuckerman JM, Assimos DG. Hypocitraturia: pathophysiology and medical management. Rev Urol 2009; 11:134-44.

34. Baraf HM, Adamson HS, Basile TC, Cole L, Doghramaji B, Guadagnoli PP, et al. Recommendations for the diagnosis and management of gout and hyperurecemia. The physician and Sports Medicine 2011; 39(4): 98-123.

35. Taylor EN, Stampfer MJ, Mount DB, Curhan GC. Re: DASH-style diet and 24-hour urine composition. J Urology 2011; 185:548-50. 